\title{
Consumer culture poetry: insightful data and methodological
}

\section{approaches.}

\section{Andrea Tonner}

Department of Marketing, University of Strathclyde, Glasgow, UK

Strathclyde Business School, Stenhouse Wing, 199 Cathedral Street, Glasgow G4 0QU.

a.tonner@strath.ac.uk

Acknowledgements: I would like to thank Canon Publishing and Andrew George for permission to reproduce "Meeting the Surrogate", Harry Giles for permission to reproduce exerts from his poetry project "Everything I bought and how it made me feel", and Bram E Gieben for permission to reproduce "Burn". I would also like to thank Andrew, Harry and Bram for participating in interviews and agreeing to be identified in this article. 


\section{Consumer culture poetry: insightful data and methodological}

\section{approaches.}

This article makes a case for greater inclusion of poetry as distinctive data within interpretive consumer research. It considers that alternative means of representation provide insight into difficult to access consumption fields. The poetic voice allows the emergence of an emic language of experience as the subject engages in self-reflexivity expressed in ways unconstrained by typical research norms. The article also considers some of the methodological choices inherent in engaging with poetic data and illustrates the research value by considering poems that unpack hidden and mundane consumption and consumer resistance. It shows how intimate experiences can be accessed and interrogated using poetic analysis, how poetry can capture the minutia of mundane consumption while laying bare the poet's reflexivity about its meaning and how the reclamation of a dead art-form can become an active form of rejection and consumer resistance.

Keywords: poetry; Sherry and Schouten; hidden consumption; mundane consumption; consumer resistance; literary criticism; textual analysis

\section{Introduction}

In interpretive consumer research, sustained interest exists in accessing the authentic emic voice of consumers within research accounts (Wallendorf and Belk, 1989). The use of diaries (Patterson, 2005), photography (Dion et al., 2014) and consumer verbatim (Corden and Sainsbury, 2006), among other sources, has longevity as evidence of the consumer within data gathering and resultant researcher interpretation. There is also a considerable heritage of textual analysis in the discipline (Stern, 1989). Indeed, this journal has been instrumental in the inclusion of textual analysis in our cannon (Stern, 
1998). Interpretive consumer research has considered artefacts as varied as biography (O’Donahoe and Turley, 2012; Stevens et al., 2015), cookbooks (Hewer and Brownlie, 2009), and even marginalia (Theophano, 2002). This paper follows the notable call of Sherry and Schouten $(2002,218)$ for consideration of poetry as part of the research enterprise; they suggest that "poetry is re-emerging as a voice of the people in places as diverse as cafes, personal websites, public buses and subways" and is a form of research material with potential for distinctive insight. Despite such notable calls for the inclusion of poetry within interpretive consumer research, it remains largely absent as a source of consumer storytelling and insight.

This article considers that there may be two reasons for this: there may be disciplinary reluctance to engage in the unfamiliarity of poetic deconstruction and a lack of value might be placed upon the data and resultant insight which poetry can provide. This article aims to encourage and enable scholars to use poetry more extensively within their research. It does this by addressing three research questions: how can scholars use poetry within consumer research, what methodological considerations are distinctive to poetic enquiry and what kinds of insights can poetic accounts of consumption illuminate. The article begins by considering the heritage of textual analysis within interpretive consumer research and the relatively scant ways in which poetry has been considered within our discipline and more broadly. It then details the methodological journey taken in gathering and addressing poetry before illustrating, through the cases of three poets' materials, the kinds of voices which poetry can capture. It demonstrates the distinctive consumption stories which poetry can tell. It gives insights into everyday and mundane consumption and hidden and vulnerable consumption, as well as anticonsumption and resistance. 


\section{Poetry and Textual Analysis in Consumer Research}

It is over a decade since consumer researchers began seriously considering poetry as a means of representing and interpreting consumer experience (e.g. Wilk, 2003). In such work, however, the consumer's poetic voice is often subservient to that of the researcher. Poetry forms part of interpretive consumer research in four broad ways: poet-researchers construct poems to represent their research insights, engage in purposeful poetic inquiry, elicit new poems from participants as part of research projects or use existing poetry or poets as data sources. Most published poetic work in interpretive consumer research involves researchers constructing poems to represent their research insights. Sherry and Schouten (2002) discuss poetry as a form of researcher reflexivity. Such work is evident within conference proceedings, including the volumes from the poetry sessions which are a regular feature of the Consumer Culture Theory Conference and where participating researcher poets perform original work inspired by their research; books (Gabel, 2016) and journals (e.g. Ozanne et al., 2011; Brown, 2014). “Consumption, Markets and Culture”' has been particularly instrumental in championing researcher poets within the discipline (Dholakia, 2005; Kozinets, 2002; Rippin, 2006; Schouten, 1997, 1998, 2003, 2007, 2009; Sherry, 2008; Wilk, 2003). Stemming from arts based qualitative inquiry (Finley, 2003), poetry emerges as one of a number of new forms of written text chosen for their unique qualities when communicating research. Ethnographic poetry, drama, and fiction (Schouten, 2014) have all been utilised to demonstrate the strength of literary forms for reporting research (Denzin, 2009). Schroeder $(2014,520)$ argues that such works "reveal boundaries and gaps in our methods of both research and writing". 
Beyond representation, Sherry and Schouten (2002) also propose the potential of poetry as a particular form of research inquiry. Zinkhan (1999) presents researcher poetry as a means of representing the postmodern and romantic in consumer behaviour but his poetry stands alone, without narrative or analysis to guide the reader. Found poetry (Butler-Kisber, 2002; Richardson, 1994), is another approach to poetic inquiry where poetry is assembled by researchers from nuggets of chained research prose. Notable among this tradition is Canniford (2012), who gives considerable detail on his process of poetic transcription and translation in which he combines a variety of data forms including diaries, telephone conversations and photographs using poetic analysis. He also discusses the strengths of such an approach, including the ability to make analytic leaps and include "an array of voices that speak for the matrix of objects, feelings and forces from which consumer culture is assembled" (Canniford, 2012, 397). In his process, poetic inquiry is not simply a means of presenting research insight; it is woven through the research process such that the poet-researcher "becomes the hub of investigation" (Canniford, 2012, 398). Sherry and Schouten $(2002,218)$ argue for poetry to be one of the only written forms to be "trusted to represent honestly and authentically the truth" while simultaneously providing opportunities for an evocative portrayal of the consumer experience such as that advocated by researcher videographers (Schembri and Boyle, 2013). Visual researchers such as Warren (2005, 886) suggest that, as interpretive researchers become concerned with immersion in their contextual worlds, photography can "almost literally act as a lens through which we see what others 'see' and importantly, deem important enough to 'capture' with a camera". While some elements of human experience are best represented visually, others elude such representation and alternatives such as poetry "which can stir us before we capture their meaning" (Wainwright, 2011, XVII) and "can communicate the actual quality of 
experience with a subtlety and precision unapproachable by any other means" (Leavis, 1972, 17), potentially become relevant.

The above uses of poetry tend to privilege the researcher's interpretation rather than the consumer's voice and experience. While useful as a research approach and a means of presenting research insights, they do not really represent a distinctive source of data; being rather more concerned with issues of data analysis and presentation. Eliciting poetic material as a form of primary data is one way to foreground the consumer experience within a research project (Hamilton et al., 2012). Wijland has a strong interest in this approach (Wijland, 2011; Wijland and Fell, 2009) and works with recognised poets to create poems specifically written for his research projects. Using poetic material as a form of primary data shares characteristics with methods such as visual research, potentially helping participants to express their feelings, beliefs and experiences and functioning either as an aid to verbal narrative or in place of it. In this respect, the creative material functions as a communicative tool whereby the research participants themselves produce the meaning (Warren, 2005). In visual analysis, Wagner (1979) calls this "native image-making" with the aim of allowing consumers to speak for as well as about themselves. It is also characteristic of Couser's (2005) discussion of autobiographical writing by research participants. In poetic inquiry we could perhaps consider this process experienced poeticism whereby consumer introspection and creativity can make both the extraordinary and mundane visible.

Finally, researchers use pre-existing poetry as a source of data. Karababa and Ger $(2011,740)$, for example, collect historical poetry as part of larger bricolage of data in their study of early ottoman coffee house culture and consider that "poetry can reflect 
official and non-official views depending on the authors' background", illuminating "different poets and their everyday life conducts". However, they give the reader no detail of any distinctive means employed to analyse their poetic materials. SomersWillet (2009) has considered the subculture of slam poetry but uses it primarily as a means of exploring the authored context. Consumption poetry has also been deconstructed within literary studies seeking insight about aesthetics, the avant garde and forms of "sensuous" knowledge where the poem stands as a form of "literary still life" (Delville, 2008, 3). Meanwhile, other social science disciplines such as human geography have considered the impact of poetry as a means of constructing and reconstructing the meaning of concepts such as place, leading to the emergence of a theory of literary geography (Alexander and Cooper, 2013). Stern (1989) has long suggested means for literary criticism to be employed in analysing consumer culture materials such as advertising. There is a tradition of utilising extant consumer culture artefacts as a means of garnering insight (Schroeder, 1997) and textual analysis has been used in interpretive consumer research to explore issues of author, reader and text (Hogg et al., 2011). Yet, application of Stern's (1989) textual approach has centred largely upon prose forms and analytics (e.g., Brownlie and Hewer, 2007). This is despite Easthope's $(2013,3)$ argument that consumer culture abounds with examples of poetry (some unofficial) "in advertising, on toilet walls, in football chants [...] by any neutral definition, they are a form of poetry".

The poetic studies highlighted in this section consider a vast range of consumption fields and issues from brand names (Schouten, 1998), through resistance and accommodation of the market (Sherry, 2008), exotic marketplaces (Dholaskia, 2005; Schouten, 1997, 2003), organisational cultures (Rippin, 2006) and even the business of 
poetry itself (Brown, 2007). As such, there is no single consumption problem to which poetic methods are most suited. Rather, poetry allows us to explore both novel consumption fields and more well-trodden consumption stories in novel ways. As Wijland and Fell (2009) discuss, prose accounts follow a structure of beginning, middle and end while poeticism enables openness to the ongoing and incomplete nature of consumption and consumer experiences. Downey (2016) suggests that poetry gives us an opportunity for a new language of consumption reaching beyond the ordinary accounts which prose can provide. As a form of research insight, poetry's largely ignored nature therefore seems at best a missed opportunity and at worst an oversight for our discipline.

\section{Methodological Approach}

This paper suggests that poetry is a distinctive form of consumer data accessible to consumer researchers given an appropriate means of analysis. Butler-Kisber (2002) argues that, as with all unfamiliar methods, methodological precision is fundamental to guard against criticism of soft or inadequate research. This paper proposes that, while no one approach to poetic material will be wholly satisfactory, interpretation which examines interrelations between the elements of poetry can be robust in exploring poetic material (Bove, 1980). As such, this section suggests some methodological considerations which have guided this research project and which other researchers should also find useful to consider.

This study has worked with three poets to consider pre-existing poetry with a strong consumption theme (Table 1). I recruited poets by accessing informal poet networks, attending poetry readings and through personal recommendations and introductions 
from poetry event organisers acting as gatekeepers to this world. Explicit informed consent has been negotiated with the authors who have given permission to reproduce their work and also to identify them through their interviews. This follows literary criticism, where the author's ownership of their creative material, including their interview opinion, is acknowledged ( $\mathrm{Li}, 2000)$.

\begin{tabular}{|l|l|l|}
\hline Poet & Poem/Collection & Poetic Tradition \\
\hline Andrew George & Meeting the surrogate/Milk Round & Page \\
Bram E Gieben & Burn & Slam/Performance \\
Harry Giles & Everything I bought and how it made & Hybrid \\
& me feel & \\
\hline
\end{tabular}

Table 1: Poet Profiles

This approach allowed me to combine three means of analysing the poetry. First, I considered close reading of the poem itself. Based on American new criticism (Easthope, 2013), this approach allows the poem itself to be considered as a consumer culture artefact created without research intent. In this tradition, the poem is an object of public knowledge, “'a verbal icon'” with embedded meaning independent of the intention of the author or critic [researcher] (Wimsatt, 1970, 5). Adopting this approach to poetry, the researcher analyses the poem by looking at the ways in which meaning is constructed, considering issues such as content, structure, style and poetic effects (Easthope, 2013). In this phase, I sought to understand the multiple codes and meanings which might be contained in a single poem or stanza. Wainwright (2011) suggests that it is a feature of poetry to analyse slowly, to read and re-read in search of meaning, and to pay attention to how techniques have created this meaning. This is akin to some of the 
close reading approaches already familiar to consumer researchers such as conversation analysis (Wetherell, 1998). Effective close reading technique directs the researcher's curiosity, drawing them into a conversation with the poem (Wainwright, 2011).

As a second stage of analysis, I followed the British tradition of poetic analysis, which argues that holding the poem as separate from the author is an unnecessary and unhelpful fiction (Easthope, 2013). This stage considers the poem as a form of author presence. In order to garner the poet's accounts of their creative intent this project gathered semi-structured interview data from the poets, each of whom brings a different approach to the discipline. This is an approach also used by Wijland (2011) in his projects of elicited poems, where he includes published biographic materials and direct personal interviews as a means of making greater sense of the poetry. My three poets have diverse backgrounds and poetic sensibilities. Andrew George published his first collection of poetry, "Milk Round", as part of the 2014 Live Canon first collection competition. Andrew is a barrister and English graduate who has worked in poetry for over 20 years. While primarily a "page poet", Andrew considers that poetry is intrinsically to be performed even when read alone and his poem "Meeting the Surrogate" forms part of this project. Bram E. Gieben is an author and performer who works across a number of forms and genres, including prose fiction, journalism and rap. Bram has performed poetry across Scotland as a solo performer and as part of a group called Chemical Poets since 2005. In 2015, this culminated in him winning the title of Scottish Slam Champion and his winning poem 'Burn'” is included in this project. He situates himself in the field of performance poetry. Harry Giles describes himself as a performer, poet and general doer of things. He makes art about protest and protests about art and writes about "'anything'. His first full collection of poetry, "Tonguit", 
was published in 2016 and, for this project, he shared his year-long poetic project “'Everything I bought and how it made me feel'. Interviews lasted between 50 minutes and two hours and were audio-recorded. Verbatim transcripts were produced.

Interviewing the poets about their work was considered valuable to this project since, as Easthope (2013) suggests, a real person formed the moment of the poem, and it is wise to seek an understanding of that moment. In addition to intra-textual analysis, this stage therefore allowed me to consider broader questions of author meaning, purpose and voice, all of which were gathered through interview.

Finally, working with three poets, I was able to consider a third level of analysis where the collected poems and interviews form an inter-textual group. In undertaking this level of analysis I could, as Canniford $(2012,398)$ suggests, draw together a range of "interdependent influences from which culture is constructed" and consider the dialogues which the combined materials create (Scheirer et al., 2016). In undertaking an inter-textual analysis, I was thus able to garner further meaning and insight across poems and poets. While some literary scholars employ quantitative methods to determine individual inter-texts and groups of inter-texts which are likely to be meaningful (Coffee et al., 2012), it is more familiar to interpretive researchers to follow a qualitative inter-textual approach (Elkad-Lehman and Greensfeld, 2011). Whether exploring phenomena (Finlay, 2009) or discourse (Roper et al., 2013), inter-textual analysis, of the type I have undertaken within this project, is commonly employed across forms of qualitative data as a means of enhancing interpretive quality criteria evidencing: trustworthiness, credibility and plausibility (Lincoln and Guba, 1999). Easthope (2013) suggests that inter-textual reading of poetry is essential if one seeks to draw these broader insights and benefits. 


\section{Consumption Insights}

Having analysed the poems and the associated interview transcripts following the procedure outlined above, I suggest that poetry can act as means of accessing consumption voices and experiences often difficult to access through more direct approaches. I discuss four insights which emerged from the data, beginning in "Poetic ways of thinking"' by discussing how the poets consider poetry as a different way of thinking about consumption and experience. I then consider three distinctive consumption stories told by their poetry, exploring insights which uncover hidden consumption, trace mundane consumption and enact anti-consumption.

\section{Poetic Ways of Thinking}

The literature suggests that poetry gives insight inaccessible through other written forms (Saunders, 2003) and certainly the poets in this project considered poetry to be a distinctive way of understanding and representing experience. Harry, for example, discusses his sense-making of the world around him:

My first response is to have some kind of artistic response to try to make something out of it and I've been writing for as long as I can remember in some form or other [...]I'm a bit magpie; I like to consider which is the best form of reacting to something. It may run as a blog but this piece I would see as poetry. (Harry)

This artistic response to the experience is relevant to consumer researchers as it represents a form of consumer reflexivity. The artist Beuys (as discussed in Borer and Schirmer, 1997) suggests that most of the thinking we do every day is routine; we repeat patterns and come up with the same solutions but artistic responses are different in that they are active forms of thought. If we want to generate new ways of considering 
experience, we should perhaps therefore engage with consumers who have spontaneously entered an active form of thinking.

Both Bram and Harry consider poetry to be one of a range of ways of expressing and capturing experience and their reactions to it. Working across a range of written and oral forms they consider that each form has distinctive things to offer and, indeed, often it is in the blurring of mediums where new expressions emerge. Bram thus suggests: We work in poetry but we may be almost actors, or film makers or activists who work in poetry, we're a very broad church and much more open to different form. It is democratised. I've got three types of poem, if it will make a good rap song it goes in that book, if it looks good on the page but I don't fancy reading it out I might put it in the page poet pile or I'll perform it. (Bram)

This blurring of medium and form relies, however, upon high levels of poetic skill. Bram, though willing to consider a democratisation of poetry through the rise of movements such as performance poetry, is conscious that good poetry and poetic thinking relies upon author skill and knowledge of the conventions and forms to allow the author to riff from them for effect. Comparing the current generation to the beat poets, he suggests that, rather than lacking rigour, slam poets " need to know the formeven if you're not going to use. The beat poets certainly knew their form even if they didn't use it. If we can't have formless poetry then you can't have Alan Ginsburg'. The blurring of mediums, he argues, allows for greater expressiveness as it allows the poet to explore elements of inspiration, intuition and imagination (Borer and Schirmer, 1997). 
All the poets agreed that one of the features of poetry which made it useful for exploring ideas differently was that, though its form provides structure, it remains a place where ideas are relatively unconstrained and can be explored in varied ways. Everyone has to write in a way that's open to interpretation because everyone brings themselves to a poem. I think in my poetry most people are going to pick up what is going on, what's more open to interpretation is your response [...] there is a sort of narrative progression but it can go off and be surreal but it's still a reality and you can see where it's going so I'm giving you a framework for interpreting. You know what it's about, you know what the words mean but you might react to that however you like. (Andrew)

The use of poetic tropes such as polemic, satire and surrealism opens up aspects of consumption not accessible in everyday speech or more documentary forms of data (Lakoff and Johnson, 1980).

The final area of agreement between the poets about the distinctiveness of the poetic way of thinking comes in the way in which language is used and the results of that language for meaning with the reader. Andrew expresses this as follows:

I think that it's the rhythm that creates memorability. Poetry is a small machine for remembering itself-however it is formed it is something which arrests attention and remains in the memory because it's beautiful but it's the rhythm which really carried this. It's much more memorable than any other form and one syllable flows on from the other in a way you cannot recall with prose no matter how much you love it. You're remembering the exact word and the exact phrasing, the exact use of language. (Andrew) 
This exacting use of language and memorability is also considered by Harry who expresses it thus:

Poetry is about dissecting language and how language works, I like learning the language of a particular experience and about exploding that and making that transparent, getting under the skin of the language we use in speech. In doing that we gain more understanding of the experience itself. In prose the language is assumed and language is a vehicle for ideas. In prose you're not supposed to see the language. In poetry you're supposed to see the language and understand that too. Understanding the distinctive language of that experience. (Harry)

These ideas of memorability and uncovering the language of an experience are useful concepts for consumer researchers, drawing upon the work of socio-communicative theorists that extra-communicative experience may only be articulated adequately once people have both sufficiency of experience and sufficiency of means and language to communicate in ways specific to that experience (Lenneberg and Roberts, 1955).

\section{Uncovering Hidden Consumption}

The poems that have been shared by the poets each have a distinctive voice. They demonstrate a variety of approaches to issues of consumption and to how poetry is crafted. Andrew George's maiden poetry collection was written over 11 years and acts as a longitudinal reflection of his experiences across that time, as he discusses: "before you're thinking about them as a book your subject matter is coalescing and you get to themes of what's happening in your life and what's important, things impinge on the action, like parenthood". This longitudinal approach was intriguing to Andrew as a way of capturing deeper insight about aspects of experience which others ignored or dealt with in a glib manner. 'I like it because there aren't that many people who do it. I 
think much writing is superficial satire and I wanted to capture the atmosphere of the centre of this world producing something much more subtle and nuanced."

Andrew's poem ' Meeting the Surrogate"' accesses a largely hidden consumption field and one which sits on the outskirts of consumer experience. Downey $(2016,358)$ has noted that poetry is a way of discussing vulnerable consumer experiences allowing "feelings in words to name an experience and to communicate what often lies hidden". Andrew's poem brings to light the experience of being outside consumer normalcy. Hochschild (2003) considers that markets and families have traditionally been seen as separate entities but Traver (2014) discusses how markets and issues of adoption (and surrogacy) may sit in tension. Andrew's poem is reproduced below:

\section{Meeting the Surrogate}

I've hired people to do things for me before.

Wiring up the outside lighting,

installing and retuning the satellite TV,

plumbing in the washer-dryer

and (to my father's shame)

driving.

Or things I could but didn't want to do.

Mowing the lawn,

filling out my tax return,

and (to my mother's shame)

ironing.

But this was different. 
I've often met new people -

at weddings, christenings, funerals,

at barbecues, on holiday,

(once) on the tube;

at corporate events,

champagne glass and vol-au-vent in hand,

mindful of my training, "Maximise Your Networking";

at parties,

Friends of friends,

Their colleagues, cousins, lovers,

Now let me introduce you to...

(my name escapes like bubbles up my glass).

But this was different.

We talked of things anyone might talk of -

the weather in Ohio,

our hopes for the Olympic summer,

the price of peanut jelly,

No I haven't met the queen.

I once saw David Beckham in a bar-

and things that they might not.

Our repeated miscarriages and desperate prognoses

Her pair of

vaginal deliveries,

her faith in God, 
how she knew that Jesus wanted her to help us in this way.

Yes, this was different.

Attempts by researchers to access insights about consumer vulnerability and hidden forms of consumption have often had to look beyond the orthodox. Andrew's discussion of surrogacy within his poem is an arresting account. Previous researchers have recognised the difficulty in asking consumers to discuss their experiences in unregulated and emotional consumption spaces. Such issues have been considered using autoethnographic methods (Ellis and Bochner, 1996) as a means of alleviating this difficulty and accessing the experience, while others have turned to texts such as biography (O’Donahoe and Turley, 2012) and Traver's (2014) discussion of adoption markets supplemented her traditional interview approach using autobiographical texts and her own experiential gestalt as a means of contextualising her data.

Close reading of Andrew's poem unpacks this uniquely personal consumer culture encounter. In the opening stanza he references the very mundane ways in which consumer culture is used to meet daily needs, those things beyond our skills and those which "should" be done at home. These are rather similar to Epp and Velagaleti's (2012) discussion of the ways in which modern parents use consumer culture resources to do those bits of parenting which are less valued.

His repetition of the phrase "this was different" throughout the poem demonstrates the contrast between surrogacy and these other consumer and social encounters in the rest of the poem; that this is not a task one would wish to have another perform. It brings out clearly the tensions felt in outsourcing this most intimate and sacred of life events. The 
poetic form, which allows for disjunction and unpredictability, works particularly well for Andrew in drawing these market tensions to the surface (Miller, 1984). Andrew himself discusses how poetry helps him to capture these experiences with such evocation:

A lot of it is the crafting; before you even write something down you have some lines. You can't just change words or lines; it might explode the whole poem but the crafting becomes more natural, you don't have to strain to get it and then you can play with it. It almost becomes so natural because [it] fits so well into your thinking and your ideas come within the form [...] it's not meant to be a realistic snapshot but you're trying to give some reflection of it. (Andrew)

In his discussion, Andrew makes clear that poetry encompasses a distinctive form of contemplation. He suggest that poetic thinking is a discrete reflexive form that doesn't manipulate the ideas of other written forms but rather allows new representations to emerge.

\section{Tracing Mundane Consumption}

The second poet, Harry, takes a very different approach to his poetry project included in this article. His poetry is in the form of a year's blog with open access rights hosted on Tumblr. He describes his own project poetically:

A year-long log of my purchases/a project to weaponize the quantified self/an auto-anthropology of the consumer subject/a self-help diary/an attempt to mine the nature of daily anxiety/a lo-res dataset about late capitalism/a car crash/a sick joke/a repetitive litany of suffering/an exploration of loser agency/a parodox of subjectivation/an exercise in hope. (Harry)

Though written in diary or blog format, Harry still very much considers this as a poetic endeavour, though he has also created a theatrical piece using the materials: 
This is the least poetic poetry I've done and it's quite a brutal aesthetic; it belongs more with internet based aesthetics, so it belongs to, like, FLARK, an American form which involves a lot of appropriation of different forms of language from the internet and post-internet poetry and both are the use of the language of the internet and the way that consumer culture permeates every form of life. "Everything I bought' belongs in that world. (Harry) As with hidden consumption (as discussed above), researcher attempts to capture consumption at its most mundane have been quite difficult. As Holttinen (2014) discusses, this is consumer behaviour which occurs in situations that the consumer perceives to be neither extraordinary nor dramatic and often characterised by routine so that consumers can find it difficult to articulate and recall. Yet, for consumer culture researchers, it is often the everyday practices of consumers which uncover insights into personal identity (Kleine et al., 1993), attachment (Wallendorf and Arnould, 1988), subcultural identity (Cronin et al., 2014) and cultural ideals (Holttinen, 2014). Harry indicates that his approach to capturing both the mundanity and meaning of everyday consumption required keeping a freshness in the work:

They're as uncrafted as anything can be. I would sit and write as soon as possible after a purchase and write all of the thought that came to mind and stop as soon as I'd finished, only editing was for typing. I liked that immediacy of response. Usually my writing is much more drafted and I'm honing an artwork but with this piece I wanted to give an uncrafted, unedited response hence its great size. (Harry)

Harry's "Everything I bought and how it made me feel"' is a truly epic work with in excess of 350 stanzas, accounting for a year of his consumption and, as such, selecting 
from it for this article was difficult. Given his expressed interest in the mundane, I have reproduced a stanza or day's entry which focuses on the most mundane:

my deal buying compulsion and my salt craving made an unholy alliance/i bought all the discount snacks/gluten free pretzels and baked broad beans and all/some of them were only five pee/it took a while to count them all/i juggled value in my head/am i saving money if i wouldn't have bought them otherwise/but if i hadn't bought these maybe i would have bought some other salty snack anyway/so maybe i did save money/but if $i$ could only fix my salt cravings/but i can't/anyway underneath this a current of pleasure at "getting a deal"/a current i'm deeply suspicious of/but still feel

Harry's poems carry argument and in writing this poetry he has also reflected a change in the way he considers his consumption. Yet he argues that this is a result of the process of creating his poetry and a response to his consumption through the form rather than a pre-meditated outcome.

It's true to say I'd no idea of the scale of the project; when I started it totally took me by surprise how much of my life it dominated. It was my work for that day and that year but I started it because I was interested in the politics and ethics of consumerism [...] I've overloaded all of my experiences and feelings about consumerism. I've come to a place where I don't really care anymore. I was delving into the experience of buying things, that consciousness of it would make me think before buying. I would try and avoid kind of making an argument, to presuppose an argument, I would try to let whatever thoughts and feelings came come and do it in that sort of immediate way. So I suppose this is both a really interesting and absurd and the whole project because about trying 
to make it makes sense and failing to make it make sense because consumerism is pretty absurd and doesn't really make sense. (Harry)

Harry's poetry has similarities to Cochrane's, as presented in Wijland (2011), where the poet flaneur works through a "pleasantly sustaining boredom, interspersed with incidental curiosities". So too Harry presents the minutia of his consumption interspersed with greater insights about his approach to consumption and the overall state of his life during the project.

\section{Enacting Anti-consumption and Resistance}

Anti-consumption can be understood as a means against consumption (Zavestoski, 2002; Lee et al., 2009) and can manifest itself as both an attitude and an activity or behaviour (Cherrier, 2009; Hogg et al., 2009). Anti-consumption can be oriented at the macro level and include discourses of dislike and acts of opposition to consumption in general or at the micro level where it is directed to particular consumption activities, products or brands (Cherrier, Black and Lee, 2011; Craig-Lees, 2006). The final poet, Bram, considers poetry as a macro level means of resisting consumer culture. By rejecting mainstream media, he considers it as a way of capturing an outsider's perspective. Bram discusses this as follows:

I'm primarily a performance poet; this allows you to look at cultural ideas from the outside. It's still fundamentally a rebel culture because it is a nascent form, it's not a funded art form, and so largely if you're performing poetry it's not going to be for the money - that allows you to be the outside and have a counter cultural voice. The poet as outsider can therefore disseminate the message of anti-capitalism. Poetry is a dead medium you don't get paid to do or don't get paid enough to live on - the fact it's a dead medium means it's more able to 
comment and criticise than it would be otherwise. If your poetry isn't tied to profit or product, isn't funded by institutions, it is quite freeing; a dead art-form can also be a revolutionary art-form. (Bram)

Lee et al. (2011) claim that anti-consumption (acts of rejection, restriction, reclamation) can overlap with consumer resistance (opposing an organisation's products, practices and partnerships). Bram's poetic work can be considered as carrying characteristics of both. Resistance to consumption can further be understood as an active manifestation of anti-consumption (Garcia-Bardida, Nau and Rémy, 2011). Consumer resistance is distinguished by its opposition against the power of institutions (Penaloza and Price, 1993). Bram considers that working outside commercial or mainstream art-forms sets the poet in opposition to the institutional power structures of those forms. He recognises that even in his work achieving a truly outside perspective is difficult:

I think that's the great contradiction of our generation; you can't criticise capitalism effectively without participating in it and you can't remove yourself from it. (Bram)

Caught in this institutional bind, Bram considers that his work is a form of satire, and acts to reclaim (Lee et al., 2011) poetry from being a dead form constrained to the page to a living medium with unique abilities to comment upon power inequity (Penaloza and Price, 1993). Reclaiming poetry in this way occurs at the ideological level where communication practices actively alter ways of thinking about consumption practices (Lee et al., 2011).

He considers that this work, included in this project "Burn", is in essence a satirical work.

\section{Burn}


The banks and ATMs are all closed down

The shops will only barter for gold teeth and family heirlooms

Except of course the banks are never closed

They trade in silent algorithms around the clock

Faster than human consciousness can calculate

That's why I'm burning all my money

I'm taking it out of the bank

Every penny and pound I can beg, borrow or steal.

Because otherwise it isn't real

I want to get the most liberating effect

From burning all my money

I'm burning all my money because

The devaluation of paper currency is inevitable anyway

And when they call in all my debts they will only send red letters

More pointless pieces of paper with no value

Or put me in a jail cell for the crime of burning all my money.

The foodbank queues are long and full of mothers

The welfare state is being sold off to pharmaceutical companies and property developers

In fact, everything I pay tax on has been sold off to corporations at a loss

Corporations which display the traits of psychopaths

I won't stand for that, I'm burning all my money. 
I'm burning all my money rather than see it bail

Out another bank that was too big to fail

Or line the pockets of another banker who should

Rightfully be in jail, and it's not like anyone will care

About my lack of wealth, my empty belly or my mental health

Things will stay exactly the same after I burn all my money.

I'm burning all my money as one in the eye

For every two car family, every celebrity

Who ever appeared on MTV cribs with a white stucco staircase

A grand piano, two Porsches and a Ferrari in the drive

Shills for a civilisation with no regard for the weak

Which champions and rewards mediocrity,

I want no part of that, I'm burning all my money

I'm burning it to staunch my guilt for

Every slave who toiled and built

This edifice in which my parents

Bore and raised and trapped me;

This hollow church of shopping malls

With blood and hair upon the walls

With flame enough I'll burn it all,

Just like I'll burn my money. 
Because you see I've realised

Until it burns I'll never be free to die,

I'll light the flame and close my eyes,

This grey parade of days will cease if you can't afford them so burn your money.

Burn your money because it makes sense

Burn it because it makes no sense

Burn it like a Buddhist monk protesting the Vietnam war

Burn it like an oilfield in Iraq captured by Allied forces

Burn it like a wicker man, burn it like a blunt

Burn it like a torture victim face held over hot coals

Burn it because you will only spend it on things that will destroy you

Burn it because the things you own end up owning you

Burn it because you need more light

Burn it because you don't own it anyway

Burn it 'cause it's an admission that everything in the system is corrupt and degraded but it can still do one thing for us

\section{IT CAN BURN}

I'm burning all my money and I'm starting today

I already feel much better now that the decision is made

I'm tearing up my mortgage and throwing it away 
Kissing my wife and kids goodbye and walking in to the sea naked and clutching nothing but

a lighter

and a fiver

You won't see me for dust

I'm burning all my money.

He describes the poem with reference to the satirical form and suggests that as a response to capitalism and associated consumerism it is the only response he knows how to make:

Historical satirists understood the kind of reality we'd be living in now. We have the tools to understand a post-capitalist world but we can't build it yet. This is a satire saying burning all your money but you can't but you do every day, $£ 3$ on a coffee this morning. Satire is the only approach to capitalism which makes sense because we're so bound up in it, we can't escape it we can't change it, it's in every facet of our lives now, hospitals, universities, everything has been devalued by it -we're at the zombie capitalism stage - everything is consumed by it all of our institutions, all of our art, all of our culture, so it's a subject I'll never leave alone. (Bram)

The theme of rejection running through "Burn' is in essence a strong discourse of anti-consumption. The concept of rejection has amassed much research from boycotting behaviours to brand avoidance (see Lee et al., 2009; Friedman, 1999). In comparison to more visible displays of anti-consumption, rejection has been described as passive because it "involves products not purchased; services not accessed; and brands not chosen" (Hogg et al., 2009, 156). Yet for Bram the ability to use poetry as a 
commentary of rejection is far from passive and in this respect he is clear that his poem is polemic:

It tends to be a didactic form-you've got limited time-you want to make one point strongly and all other points to support that. For my own work I also like ambiguity. I think satire depends on ability to read subtext. (Bram)

Interrogating the poem further, he uses repetition and alliteration and what he discusses as "ugly metaphors and crippled similes" such as "This hollow church of shopping malls, With blood and hair upon the walls" to make this strongly polemic point. It is argued that his use of metaphor is particularly apt in this regard as it makes coherent aspects of experience which are difficult to capture through other means (Lakoff and Johnson, 1980).

\section{Discussion}

This article has been a response to a longstanding call for the inclusion of poetic voices within interpretive consumer research (Sherry and Schouten, 2002). It has offered some methodological considerations and also a glimpse of some of the ways in which insight into difficult to access consumption theories can be illuminated through these alternative means of representation. It proposes that use of poetry offers three contributions to consumer research: poetry extends the language of consumption and the scope of our understanding; consumer-poets combine lived experience and skilled reflexivity, making their accounts unique rather than commonplace; and poetry is a form of consumer experience in its own right.

The first contribution of this paper is to suggest that poetry gives the research subject control of the language of consumption and that poetic language extends the horizons of 
understanding. Poetry opens up issues and experiences inadequately captured by prose. This paper has considered the notion that there is a distinctiveness in the poetic voice when measured against our existing arsenal of data collection methods and means of representation and that this comes through a particular poetic way of thinking (Saunders, 2003). Their distinctive use of language means that, rather than the researcher imposing a language of experience through their interpretation of text, the subject controls that language of experience widening beyond our common vocabulary (Lenneberg and Roberts, 1955). Further, the research subject engages in self-reflexivity and active thinking around experiences, which means that their accounts of consumption are unconstrained by the norms of speech or prose (Lakoff and Johnson, 1980). Previous consumer researchers (e.g. Downey, 2016) have considered how poetry can be particularly illuminating in particular consumption contexts (e.g. vulnerability), but this paper suggests that, regardless of context (extraordinary or mundane), poetry brings a distinctive lexicon.

Second, the article has demonstrated that distinctive insights are inherent in poetry. Poetry can tell difficult to reach consumption stories in ways which are unfamiliar within current consumer research and so prove additionally insightful. Considering two reasonably heavily researched forms of consumption which have been considered highly relevant to consumer research - hidden consumption (Traver, 2014) and mundane consumption (Holttinen, 2014) - additional insight and nuance have been added to the concepts through consideration of poetic data because the consumer-poet combines lived experience and skilled reflexivity. 
In the area of hidden consumption, poetry allows the intimate experience of the consumer to be preserved in the "artefact" of his or her poetry while simultaneously providing analytic distance, giving the researcher the opportunity to interrogate the creation of that story and its meaning. Traver $(2014,218)$ has noted that "researchers struggle to connect with the community" in hidden and vulnerable consumption situations and that, as such, reaching their secrets can be difficult. Conversely, she notes that, in trying to overcome that issue, perhaps through the sensitising perspective of an auto-experience, the researcher can face issues of emotional objectivity and distance. The poetic account allows the researcher to access secrets while preserving their own research focus. Combining the range of analysis approaches discussed earlier, the researcher can unpick both the close detail of the written text and the poetic intent (Easthope, 2013) to draw out the tensions inherent in these hidden consumption markets.

Poetry combines the minutia of the everyday with consumer reflexivity in unpacking mundane consumption. Mundane consumption, like hidden consumption, has been considered a difficult form of consumption to access. Either it is so everyday that consumers fail to see it or they seek to tell the extraordinary and special stories within it (Holttinen, 2014). Stream of consciousness poetry, which blurs media, allows for a repository of both the minutiae of detail that mundane consumption accounts require but also active thinking by the consumer-poet about the meaning and consequences of the mundane. This combination of closeness and distance, immediacy and reflexivity, by the consumer which we find in poetry is less evident in more traditional research accounts and extends Wijand's (2011) view that while narratives follow the welltrodden path, poetry has a particularism to access alternative tales. 
Finally, poetry emerges from this research as a form of consumer experience in its own right as a means of enacting consumer resistance (Penaloza and Price, 1993). Consumer resistance and anti-consumption is a vibrant research area (Lee et al., 2011) and the connections between the attitudes and acts it encompasses continue to be explored. In this paper, an exploration of the poetry of consumer resistance makes it apparent that, contrary to prior theorisation of consumer rejection as a passive form of consumer resistance (Hogg et al., 2009), rejection can be active and considered. Rejecting commercially viable art-forms allows the poet to express forcefully a voice of the outsider. It negotiates the tension felt at the institutional bind of consumer culture participation, allowing the poet to reclaim a dead art-form for contemporary expression and illustrating how forms of anti-consumption can be used in combination for greater effect and impact.

As the first direct consideration of pre-existing poetry in consumer research in some years, this article cannot hope to convey the scope of all that poetry can reveal about consumer experience nor can it hope to be exhaustive in the methodological approaches appropriate to its interpretation. Much further research is required to bring this textual form into the research orthodoxy. Different poetic forms and traditions are likely to generate different insights and a deeper examination of the subgenres of poetry such as performance poetry would allow a deeper understanding of the voices in particular poetic subcultures. It is my hope that this article encourages a reconsideration of this " dead" art-form, which is being used in such vibrant and varied ways by contemporary poets. 
Finally I suggest that this article gives impetus to consumer researchers to reconsider other under-utilised consumer culture artefacts and research methods which focus on subject controlled language, experiences or reflexivity. If poetry can capture distinctive consumption, market or cultural insights then surely other neglected or forgotten aspects of our cultural arsenal can be just as fruitful. Ethnographers, for example, continue to explore ways of understanding embodiment and to seek novel methodological approaches such as Feldenkrais method in its examination (e.g. Luraschi, 2017). Consumer researchers also have much to learn by pushing the methodological boundaries of our discipline. Visual and textual methods are increasingly part of our orthodoxy yet much remains to under-explored in the unorthodox.

\section{References}

Alexander, Neil, and David Cooper. 2013. Poetry \& Geography: Space \& Place in Post-war Poetry. Oxon: Oxford University Press.

Borer, Alain, and Lothar Schirmer. 1997. The Essential Joseph Beuys. Cambridge: Mit Press.

Bové, Paul. 1980. Destructive Poetics: Heidegger and Modern American Poetry. New York: Columbia University Press.

Brown, Stephen. 2007. "Selling poetry by the Pound: T.S. Eliot and The Waste Land brand." Consumption, Markets \& Culture 18 (5): 411-426.

Brown, Stephen. 2014. "Petals on a Wet, Black Brand: The Place of Poetry in Consumer Culture Theory.” In John W. Schouten, Dianne M. Martin, and Russell W. Belk, eds. 2014. Research in Consumer Behaviour Vol 16 Consumer Culture Theory. Bingly: Emerald. Brownlie, Douglas, and Paul Hewer, 2007. "Prime Beef Cuts: Culinary Images for Thinking 'Men'." Consumption, Markets \& Culture 10 (3): 229-250. 
Butler-Kisber, Lynn. 2002. “Artful Portrayals in Qualitative Inquiry: The Road to Found Poetry and Beyond." The Alberta Journal of Education Research XLVIII (3): 229-239.

Canniford, Robin. 2012. "Poetic Witness: Marketplace Research through Poetic Transcription and Poetic Translation.'” Marketing Theory 12 (4): 391-409.

Cherrier, Hélène. 2009. “Anti-consumption Discourses and Consumer Resistant Identities.” Journal of Business Research 62: 181-190.

Cherrier, Hélène, Iain R. Black, and Mike Lee. 2011. "Intentional Non-consumption for Sustainability: Consumer Resistance and/or Anti-consumption?” European Journal of Marketing 45 (11/12): 1757-1767.

Coffee, Neil, Jean Pierre Koenig, Shakthi Poornima, Rolenat Ossewaarde, Christopher Forstall and Sarah Jacobson. 2012. "Intertextuality in the Digital Age." Transactions of the American Philological Association 142 (2): 383-422.

Corden, Ann and Roy Sainsbury. 2006. “Exploring 'Quality': Research Participants' Perspectives on Verbatim Quotations." International Journal of Social Research Methodology 9 (2): 97-110.

Couser, Thomas. 2005. “Disability, Life Narrative, and Representation.” In L. J. Davis, eds. 2005. The Disability Studies Reader 2nd ed. New York: Routledge, 104-112.

Craig-Lees, Margret. 2006. “Anti-consumption: Concept Clarification and Changing Consumption Behavior." Paper presented at the anti-consumption seminar, International Centre for Anti-Consumption Research, 20-21 June, Auckland, New Zealand

Cronin, James. M., Mary B. McCarthy, and Alan M. Collins. 2014. "Covert Distinction: How Hipsters Practice Food-based Resistance Strategies in the Production of Identity." Consumption, Markets \& Culture, 17 (1): 2-28.

Denzin, Norman K. 2009. "The Elephant in the Living Room: Or Extending the Conversation about the Politics of Evidence.” Qualitative Research 9: 139-160.

Delville, Michel. 2008. Food, Poetry and the Aesthetics of Consumption: Eating the Avant-garde. Oxon: Routledge.

Dholakia, Nikhilesh. 2005. "Poetry." Consumption, Markets and Culture 8 (2): 183-189. 
Dion, Delphine, Ouidade Sabri, and Valerie Guillard. 2014. "Home Sweet Messy Home: Managing Symbolic Pollution.” Journal of Consumer Research 41 (3): 565-589.

Downey, Hilary. 2016. "Poetic Inquiry, Consumer Vulnerability: Realities of Quadriplegia." Journal of Marketing Management 32 (3/4): 357-364.

Easthope, Antony. 2013. Poetry as Discourse. Oxon: Routledge.

Elkad-Lehman, Ilana, and Hava Greensfeld. 2011. "Intertextuality as an Interpretative Method in Qualitative Research.” Narrative Inquiry 21 (2): 258-275.

Ellis, Caroline, and Albert P. Bochner, eds. 1996. Composing Ethnography: Alternative Forms of Qualitative Writing. Walnut Creek: Rowman Altamira.

Epp, Amber, and Sunaina Velagaleti. 2012. “'Outsourcing Motherhood: Managing Assemblages of Care." NA-Advances in Consumer Research 40: 18-21.

Finlay, Linda. 2009 "Debating Phenomenological Methods." Phenomenology \& Practice. 3 (1): 6-25.

Finley, Susan. 2003. "Arts-Based Inquiry in QI: Seven Years From Crisis to Guerrilla Warfare.” Qualitative Inquiry 9 (2): 281-296.

Friedman, Munro. 1999. Consumer Boycotts. London: Routledge.

Garcia-Bardida, Renaud, Jean-Philippe Nau and Eric Rémy. 2011. “Consumer Resistance and Anti-consumption: Insights from the Deviant Careers of French Illegal Downloaders.” European Journal of Marketing 45 (11/12), 1789-1798.

Gabel, Terrance, ed. 2016. "Poetically Considering Death and its Consumption." In Susan Dobscha, ed. 2016 Death in Consumer Culture. London: Routledge.

Hamilton, Kathy, Beverley Wagner, and Juliette Wilson. 2012. "Food and Nostalgia - Poetic Representations in Culinary Cultures: An Exploration of Three Culinary Texts." Paper presented at 7th Consumer Culture Theory Conference. Oxford.

Hewer, Paul and Douglas Brownlie. 2009. “Nigella', an Iconic Brand in the Baking: Culinary Culture, Gastrobrands and Identity Myths." NA - Advances in Consumer Research 36: 482487. 
Hochschild, Jennifer L. 2003. "'Social Class in Public Schools." Journal of Social Issues 59 (4): $821-840$

Hogg Margaret, Pauline Maclaran, Lydia Martens, Stephanie O’Donohoe, and Lorna Stevens. 2011. “(Re)creating Cultural Models of Motherhoods." Contemporary Advertising \& Society Review 2 (12).

Hogg, Margaret K., Emma N. Banister, and Christopher A. Stephenson. 2009. "Mapping Symbolic (Anti-) Consumption.” Journal of Business Research 62: 48-159.

Holttinen, Helli. 2014. "How Practices Inform the Materialization of Cultural Ideals in Mundane Consumption." Consumption, Markets \& Culture 17 (6): 573-594.

Karababa, Emınegül, and Gülız Ger. 2011. “Early Modern Ottoman Coffeehouse Culture and the Formation of the Consumer Subject." Journal of Consumer Research 37: 737-760.

Kleine, Robert. E., Susan S. Kleine and Jerome B. Kernan. 1993. “Mundane Consumption and the Self: A Social-identity Perspective. Journal of Consumer Psychology 2 (3): 209-235.

Kozinets, Robert V. 2002. "Desert Pilgrim.” Consumption, Markets and Culture 5 (2): 171-186. Lakoff, George and Mark Johnson. 1980. "Conceptual Metaphor in Everyday Language.” The journal of Philosophy, 77(8), 453-486.

Leavis, Frank. R. 1972. Bearings in English Poetry. London: Pelican.

Lee, Michael S. W., Karen Fernandez, and Michael R. Hyman. 2009. “Anti-consumption: An Overview and Research Agenda." Journal of Business Research 62 (2): 145-147.

Lee, Mike, Dominique Roux, Helene Cherrier, and Bernard Cova. 2011. "Anti-consumption and Consumer Resistance: Concepts, Concerns, Conflicts and Convergence.” European Journal of Marketing (11/12): 1680-1687.

Lenneberg, Eric H., and John Milton Roberts. 1955. The Language of Experience: A Study in Methodology. Mass.: MIT Press.

Li, David L. 2000. Imagining the Nation: Asian American Literature and Cultural Consent. Stanford: Stanford University Press.

Lincoln, Yvonne S., and Egon G. Guba. 1999. Naturalistic Inquiry. CA: Sage. 
Luraschi, Silvia. 2017. "Living reflexively in the research: auto-ethnography in embodied pedagogy." Proceedings of the European Congress of Qualitative Inquiry: 34-43

Miller, Patrick D. 1984. "Meter, Parallelism, and Tropes: The Search for Poetic Style.” Journal for the Study of the Old Testament 9 (28): 99-106.

O’Donohoe, Stephanie, and Daragh Turley. 2012. "The Sadness of Lives and the Comfort of Things: Goods as Evocative Objects in Bereavement." Journal of Marketing Management 8 (11-12): 1331-1353.

Ozanne, Julie, S. Pettigrew, D. Crockett, F. A. Firat, H. Downey, and M. Pescud. 2011. “The Practice of Transformative Consumer Research - Some Issues and Suggestions.' Journal of Research for Consumers 19: 1-7.

Patterson, Anthony. 2005. "Processes, Relationships, Settings, Products and Consumers: The Case for Qualitative Diary Research.” Qualitative Market Research: An International Journal 8 (2): 142-156.

Penaloza, Lisa and Linda L. Price. 1993. "Consumer Resistance: A Conceptual Overview.” Advances in Consumer Research 20 (1): 123-128.

Richardson, Laurel. 1994. "Nine Poems.'” Journal of Contemporary Ethnography 23 (1): 3-13. Rippin, Ann. 2006. "Invitation to the Journey: The Consolations of Organisational Excess." Consumption, Markets and Culture 9 (2): 137-143.

Roper, Stuart, Robert Caruana, Dominic Medway, and Phil Murphy. 2013. “Constructing Luxury Brands: Exploring the Role of Consumer Discourse.” European Journal of Marketing 47 (3/4): 375-400.

Saunders, Lesley. 2003. “'On Flying, Writing Poetry and Doing Educational Research.” British Educational Research Journal 29 (2): 175-187.

Scheirer, Walter, Christopher Forstall, and Neil Coffee. 2016. "The Sense of a Connection: Automatic Tracing of Intertextuality by Meaning.’' Digital Scholarship in the Humanities 31 (1): 204-217.

Schembri, Sharon, and Maree V. Boyle. 2013. "Visual Ethnography: Achieving Rigorous and Authentic Interpretations.” Journal of Business Research 66: 1251-1254. 
Schouten, John W. 2014. “'My Improbable Profession.' Consumption, Markets and Culture 17 (6): 595-608.

Schouten, John W. 2009. “'A Study in Loss: Six Poems.” Consumption, Markets and Culture 12 (4): 389-392.

Schouten, John W. 2007. “Poems.” Consumption, Markets and Culture 10 (4): 481-483.

Schouten, John W. 2003. "Consumption and Production in Two Oaxacan Communities." Consumption, Markets and Culture 6 (2): 145-152.

Schouten, John W. 1998. "When a Rose is Eros: A Demianagramatical Study of Brand Names." Consumption, Markets and Culture 2 (4): 449-455.

Schouten, John W. 1997. “Trivium Siam.” Consumption, Markets and Culture 1 (1): 90-95.

Schroeder, Jonathan. 2014. "Editorial.” Consumption, Markets \& Culture 17 (6): 519-521.

Schroeder, Jonathan. 1997. "Andy Warhol: Consumer Researcher." Advances in Consumer Research 24: 476-482.

Sherry, John F., and John W. Schouten. 2002. “A Role for Poetry in Consumer Research.” Journal of Consumer Research 29 (2): 218-234.

Sherry, John F. 2008. "Three Poems on Markets and Consumption.” Consumption, Markets \& Culture 11 (3): 203-206.

Somers-Willet, Susan. 2009. The Cultural Politics of Slam Poetry: Race, Identity, and the Performance of Popular Verse in America. Michigan: University of Michigan Press.

Stern, Barbara. 1998. “Deconstructing Consumption Text: A Strategy for Reading the (Re)constructed Consumer.' Consumption, Markets \& Culture 1 (4): 361-392.

Stern, Barbara. 1989. "Literary Criticism and Consumer Research: Overview and Illustrative Analysis." Journal of Consumer Research 16 (3): 322-334.

Stevens, Lorna, Benedetta Cappellini, and Gilly Smith. 2015. "Nigellissima: A Study of Glamour, Performativity and Embodiment.” Journal of Marketing Management 31 (5-6): $577-598$.

Theophano, Janet. 2002. Eat My Words: Reading Women's Lives through the Cookbooks They Wrote. New York: Palgrave. 
Traver, Amy E. 2014. “'Becoming a 'Chinese-American Parent: Whiteness, Chinese Cultural Practice, and American Parents of Children Adopted from China.' In Vilna B. Reitler, ed. 2014. Race in Transnational and Transracial Adoption. UK: Palgrave Macmillan: 226-241. Wagner, John, 1979. Images of Information. London: Sage.

Wainwright, Jeffrey. 2011. Poetry the Basics $2^{\text {nd }}$ edition. Oxon: Routledge.

Wallendorf, Melanie, and Eric J. Arnould. 1988. "My Favorite Things: A Cross-cultural Inquiry into Object Attachment, Possessiveness, and Social Linkage.” Journal of Consumer Research 14 (4): 531-547.

Wallendorf, Melanie, and Russell W. Belk. 1989. “Assessing Trustworthiness in Naturalistic Consumer Research.” In E. C. Hirschman, ed. 1989. Interpretative Consumer Research. Association of Consumer Research.

Warren, Samantha. 2005. "Photography and Voice in Critical Qualitative Management Research.” Accounting, Auditing \& Accountability Journal 18 (6): 861-882.

Wetherell, Margaret. 1998. "Positioning and Interpretative Repertoires: Conversation Analysis and Post-structuralism in Dialogue." Discourse \& Society 9 (3): 387-412.

Wijland, Roel. 2011. “Anchors, Mermaids, Shower-curtain Seaweeds and Fish-shaped Fish: The Texture of Poetic Agency." Marketing Theory 11 (2): 127-141.

Wijland, Roel, and Cliff Fell. 2009. "Critical Brand Poetics: 'from The M at the End of the Earth'.', Journal of Marketing Management 5 (7-8): 745-761.

Wilk, Richard. 2003. "Poems on the Theme of 'Gleaning'.' Consumption, Markets \& Culture 6 (3): 183-204.

Wimstatt, William K. 1970. The Verbal Icon: Studies in the Meaning of Poetry. London: Methuen.

Zavestoski, Stephen. 2002. "Guest Editorial: Anti-consumption Attitudes.” Psychology \& Marketing 19 (2): 121-126.

Zinkhan, George N. 1999. "Capturing Consumption through Poetry: Postmodernism and Romanticism in Consumer Behavior." NA-Advances in Consumer Research 26: 251-252. 